Original Research Article

\title{
Self-medication practices of over the counter analgesics among first and third semester undergraduate medical students in a tertiary care medical college, Jharkhand
}

\author{
Kusum Kumari ${ }^{1}$, Manju Gari ${ }^{1}$, Mary Sunita Toppo ${ }^{1}$, Ira Anupama Soreng ${ }^{2}$, Priyanki $^{1}$ *
}

${ }^{1}$ Department of Pharmacology and Therapeutics, ${ }^{2}$ Department of Physiology, Rajendra Institute of Medical Sciences, Ranchi, Jharkhand, India

Received: 13 September 2019

Revised: 07 November 2019

Accepted: 11 November 2019

*Correspondence to:

Dr. Priyanki,

Email: priyanki.mishra@ gmail.com

Copyright: () the author(s), publisher and licensee Medip Academy. This is an openaccess article distributed under the terms of the Creative Commons Attribution NonCommercial License, which permits unrestricted noncommercial use, distribution, and reproduction in any medium, provided the original work is properly cited.

\begin{abstract}
Background: Self-medication is a widely practiced trend in the general Indian population. Among the medical students, self- medication is popular because of awareness about the disease and their treatment. Analgesics are one of the most common drugs used for self-medication. Very few studies are available in Jharkhand regarding this subject. So, the present study aims to delve into the pattern of self-medication practices of analgesics among the $1^{\text {st }}$ and $3^{\text {rd }}$ semester medical students of RIMS, Ranchi, Jharkhand.

Methods: A questionnaire based cross sectional study was done in RIMS, Ranchi, Jharkhand, India in March-April 2019 among the undergraduate medical students. The results were expressed as percentage and frequency.

Results: Out of total 150 and 142 students in the $1^{\text {st }}$ and $3^{\text {rd }}$ semester respectively, 140 and 130 students practiced self- medication. Advice from seniors was the biggest source of information in both the groups followed by internet and books. Paracetamol was the most common drug $(75 \% ; 60 \%)$ and headache was the most common indication $(55 \%$; 68\%). Quick relief of symptoms was the most common reason for self-medication in both the groups (44\%; 48\%).

Conclusions: In both the groups, the students continued the drug even after experiencing side effects $(77 \% ; 60 \%)$. Most students were of the view that such practice is not acceptable at all times $(75 \% ; 72 \%)$.
\end{abstract}

Keywords: Self-medication practices, Medical students, Analgesics, Nonsteroidal anti-inflammatory drugs, Indian population

\section{INTRODUCTION}

The intake of any type of drugs for treating oneself without professional supervision to relieve an illness or a condition is defined as self-medication. ${ }^{1}$ According to World Health Organisation, responsible self-medication can help in the prevention and treatment of the diseases that do not require medical consultation; they are pocket friendly too. ${ }^{2}$ But, self-medication must be accompanied by appropriate knowledge about health issues. ${ }^{3}$ Selfmedication is always without any proper diagnosis and may involve more than one medicine; often including herbal remedies. Several factors are involved in the selfmedication practices which include the level of education, personal belief, nature of the disease and access to the media. ${ }^{4}$ Simplicity of disease and recurrences also can be a frequent cause of selfmedication practices.

Multiple problems related to self-medication include increased risk of adverse drug reactions, drug interactions, drug resistance, and even sudden death in certain cases. These eventualities can be contributed both to prescription drugs used on an individual's own initiative and misuse or abuse of over the counter medicines. Yet, self-medication is considered advantageous in certain situations. ${ }^{5}$

A study in Jordan shows that the classification of medicine as prescription-only-medicine and over-thecounter (OTC) drugs is present but not enforced on community pharmacies. This allows a wider range of 
medications to be accessible to the public that otherwise are provided only on prescription. Thus, the safety and effectiveness of the pharmacotherapy in question is at stake. $^{6}$

Easy availability leads to over use of over the counter drugs.

All over the world, the prevalence of self-medication is high. In the developing countries, it is high with $92 \%$ in Kuwait, $76 \%$ in Pakistan and $59 \%$ in Nepal. In European countries, it is as low as $68 \% .^{7}$ According to a study in Karachi, the frequency of self-medication is very high in university students with $77.7 \%$ in medical students and $83.3 \%$ in non-medical students. ${ }^{8}$

Though the medical students are not legally permitted to prescribe, they always like to prescribe for themselves and others as they are gaining new knowledge about the disease and drugs and want to acquire better skills in the use of medicines. ${ }^{9}$

Previously, a number of research work has been done both in India and outside on this issue as it can have several socioeconomic consequences; both positive and negative. In Jharkhand, very few studies have been done on this subject so far. Keeping this in mind, this study has been conducted to estimate the prevalence of selfmedication in $2^{\text {nd }}$ and $3^{\text {rd }}$ year students of RIMS, Ranchi.

\section{METHODS}

Out of 150 students in the $1^{\text {st }}$ semester, 146 students participated in the study whereas 6 students were absent. In the $3^{\text {rd }}$ semester, 137 out of 142 students participated in the study whereas 5 were absent. Thus, the data of 283 students were eligible for analysis.

This study was a questionnaire based cross sectional study conducted MBBS students of RIMS Ranchi, Jharkhand. The first and fourth year students of this college were included in this study. Filled questionnaires were evaluated for their completeness and only the data from completely filled questionnaire was taken for analysis. Incompletely filled questionnaires were excluded from the study. The study was conducted in Department of Pharmacology between 1st March to 30th April 2019. The students who participated in the studies were explained about aim of the study. They were ensured about confidentiality of the information collected. A self-prepared questionnaire regarding the practice of OTC analgesic drugs were given to them. The questionnaire had questions related to practice of self-medication for any type of pain, sources of drug information, name of analgesic used with indication, reason for self-medication, frequency and duration of intake, any side effects experienced and lastly opinion about self-medication. The questionnaire was given to them during one of their lecture classes and was asked to return it after filling it completely. All questions were multiple choice questions and they had to tick only correct answers.

The data was then analyzed for the different genders of students in each year who used self-medication. The most common source of information about drugs for these medical students was analyzed by studying the questionnaires carefully. Types of analgesics used and their indications were also noted down. The common reasons for self-medication and the total number of tablets used daily was studied. Duration of drug intake, time of taking the medicines and their side effects were also evaluated. Responses to side effects and opinion regarding self-medication were also accounted for.

\section{Statistical analysis}

All data were expressed in the form of frequency and percentage. Chi-square test was used for testing statistical significance. A p value less than 0.05 was considered to be statistically significant.

\section{RESULTS}

Table 1 shows that among $1^{\text {st }}$ semester students, participating in the study $46 \%$ were male and $54 \%$ were females. Among the $3^{\text {rd }}$ year students, 42 and $58 \%$ belonged to the male and female gender respectively. Total no of students indulging in self-medication were 140 in the $1^{\text {st }}$ and 130 in the $3^{\text {rd }}$ semester which is evident from the Table 2 .

Table 1: Gender distribution.

\begin{tabular}{|lll|}
\hline Gender & First semester & Third semester \\
\hline Male & $\mathbf{N}(\boldsymbol{\%})$ & $\mathbf{N}(\boldsymbol{\%})$ \\
\hline Female & $65(46.43)$ & $55(42.31)$ \\
\hline Total & $75(53.57)$ & $75(57.69)$ \\
\hline
\end{tabular}

Table 2: Practice of self-medication-first and third semester $(n=150)$.

\begin{tabular}{|lll|}
\hline $\begin{array}{l}\text { No. of students } \\
\text { consented }\end{array}$ & First semester & Third semester \\
\hline Yes & $\mathbf{N}(\mathbf{\%})$ & $\mathbf{N}(\mathbf{\%})$ \\
\hline No & $140(93.33)$ & $130(91.55)$ \\
\hline Absent & $6(4)$ & $7(4.93)$ \\
\hline Total & 150 & $5(3.52)$ \\
\hline
\end{tabular}

Advice from seniors was the main source of information in both the $1^{\text {st }}$ and $3^{\text {rd }}$ semester $(85 \%, 76 \%)$ according to Table 3. Books and internet were other important sources of information.

Table 4 shows the most commonly used analgesics in the students of both the semesters. Paracetamol was the most commonly used analgesic $(75 \% ; 60 \%)$. The $2^{\text {nd }}$ 
most common analgesic in $1^{\text {st }}$ semester students was Meftal spas (9\%) whereas the $3^{\text {rd }}$ semester students used aspirin more $(13 \%)$. Use of Combiflam was more in the $3^{\text {rd }}$ semester than in the $1^{\text {st }}$ semester $(7 \% ; 9 \%)$.

Table 3: Source of information.

\begin{tabular}{|lll|}
\hline \multirow{2}{*}{ Source of information } & $\begin{array}{l}\text { First } \\
\text { semester }\end{array}$ & $\begin{array}{l}\text { Third } \\
\text { semester }\end{array}$ \\
\hline N (\%) & $\mathbf{N}(\%)$ \\
\hline Internet & $17(12.14)$ & $29(22.3)$ \\
\hline Books & $18(12.86)$ & $5(38.4)$ \\
\hline Old prescriptions & $16(11.43)$ & $16(12.3)$ \\
\hline $\begin{array}{l}\text { Media and } \\
\text { advertisements }\end{array}$ & $6(4.29)$ & $4(30.7)$ \\
\hline Advice from seniors & $83(59.29)$ & $76(58.4)$ \\
\hline Total & 140 & 130 \\
\hline
\end{tabular}

Table 4: Analgesics used.

\begin{tabular}{|lll|}
\hline Name of analgesic & $\begin{array}{l}\text { First } \\
\text { semester }\end{array}$ & $\begin{array}{l}\text { Third } \\
\text { semester }\end{array}$ \\
\hline N (\%) & N (\%) \\
\hline Paracetamol & $105(75)$ & $78(60)$ \\
\hline Aspirin & $1(0.71)$ & $17(13.08)$ \\
\hline Combiflam & $10(7.14)$ & $12(9.23)$ \\
\hline Meftal spas & $12(8.57)$ & $11(8.46)$ \\
\hline Zerodol-P & $0(0)$ & $5(3.85)$ \\
\hline Zerograin & $0(0)$ & $3(2.31)$ \\
\hline Aceclofenac & $7(5)$ & $2(1.54)$ \\
\hline Sumo & $4(2.86)$ & $1(0.77)$ \\
\hline Flexon- MR & $1(0.71)$ & $1(0.77)$ \\
\hline Total & 140 & 130 \\
\hline
\end{tabular}

Table 5: Indications for analgesics.

\begin{tabular}{|lll|}
\hline Indication & $\begin{array}{l}\text { First } \\
\text { semester }\end{array}$ & $\begin{array}{l}\text { Third } \\
\text { semester }\end{array}$ \\
\hline Headache & $55(39.29)$ & N $(\%)$ \\
\hline Cold and flu & $15(10.71)$ & $5(32.31)$ \\
\hline Fever & $48(34.29)$ & $36(27.69)$ \\
\hline Abdominal pain & $4(2.86)$ & $4(3.08)$ \\
\hline Muscular pain & $12(8.57)$ & $5(3.85)$ \\
\hline Menstrual pain & $6(4.29)$ & $12(9.23)$ \\
\hline Total & 140 & 130 \\
\hline
\end{tabular}

Table 5 shows the common indications for analgesic use by oneself. The most common indication is headache in both the groups $(39 \% ; 52 \%)$ followed by fever $(34 \%$; $28 \%$ ). Cold and flu followed after this in the $1^{\text {st }}$ semester $(11 \%)$ whereas in the $3^{\text {rd }}$ semester, menstrual pain was the $3^{\text {rd }}$ important cause $(9 \%)$.

The various reasons for self-medication have also been sought for. Quick relief of symptoms (44\%; 48\%) followed by mild nature of the illness $(29 \%, 23 \%)$ are mainly responsible for the common self-medicated analgesic use. Time saving was an important purpose for self-medication in the $1^{\text {st }}$ semester students $(11 \%)$ whereas the $3^{\text {rd }}$ semester students were more selfconfident regarding self-medication practices $(15 \%)$.

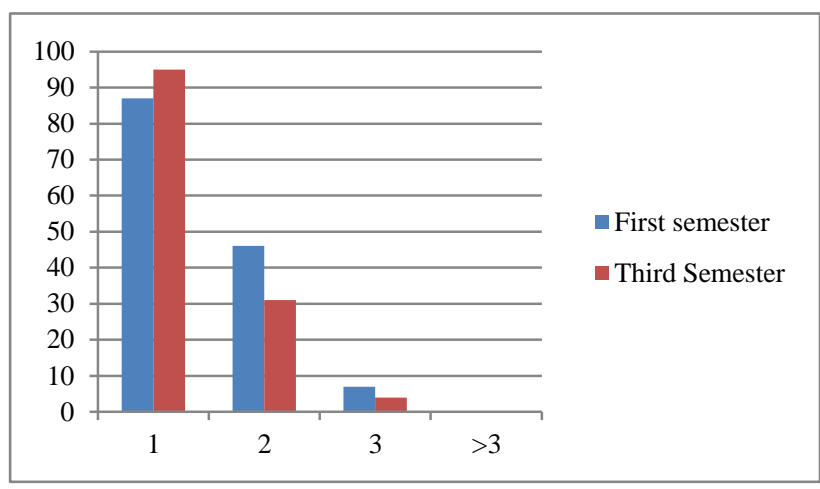

Figure 1: Number of tablets per day.

In the Figure 1, the number of tablets taken per day has been shown. In the $1^{\text {st }}$ semester, a single tablet was used by $62 \%, 2$ tablets per day were taken by $33 \%$ of the students whereas $5 \%$ of the students took 3 tablets per day. In the $3^{\text {rd }}$ semester, $73 \%$ of the students took a single per day, $23 \%$ used 2 tablets per day and $3 \%$ used 3 tablets per day. Not a single student used more than three tablets in either semester.

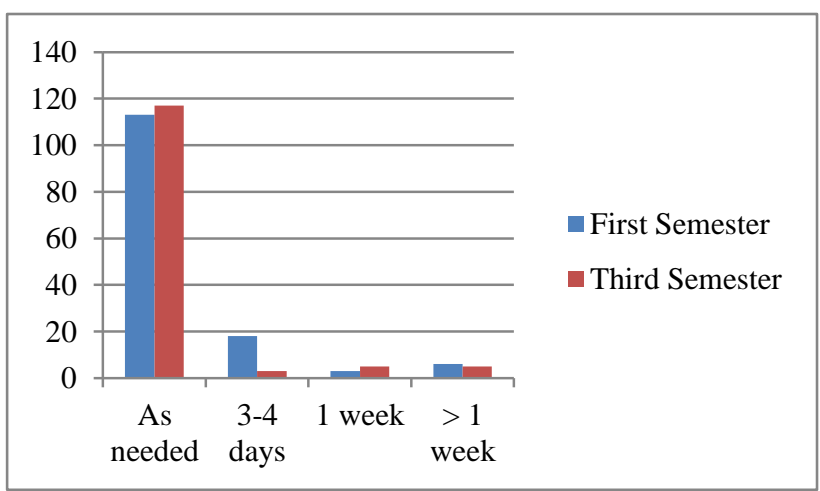

Figure 2: Duration of taking analgesics.

Figure 2 depicts the total duration of analgesic use by the students. $80 \%$ of the $1^{\text {st }}$ semester students were using self-medication as per requirement whereas this figure was $90 \%$ in the $3^{\text {rd }}$ semester. $12 \%$ of $1^{\text {st }}$ semester students took the treatment for 3-4 days whereas only $2 \%$ of the students of the $3^{\text {rd }}$ semester used it for this duration. $2 \%$ and $3 \%$ of students took self-medication for a week in the $1^{\text {st }}$ and $3^{\text {rd }}$ semester whereas $6 \%$ and $5 \%$ of the students took it for more than one week respectively.

Figure 3 shows the time of taking the analgesics. Almost negligible amount of students took it before meal whereas $59 \%$ and $50 \%$ of the students of $1^{\text {st }}$ and $3^{\text {rd }}$ semester took it after meals. $30 \%$ and $40 \%$ of the students took it during the episodes of pain. 

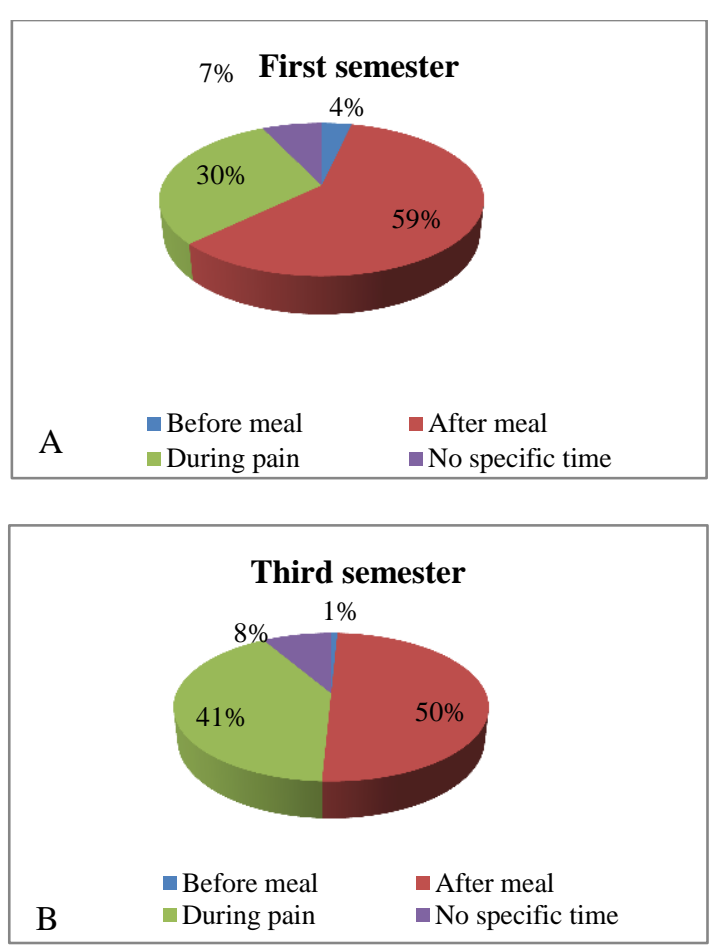

Figure 3 (A-B): Time of taking drugs.

The Figure 4 shows the side effects that the students faced. Gastric irritation was seen in $44 \%$ and $32 \%$ of the students of both the semester whereas $33 \%$ and $35 \%$ of the students did not experience any side effect. Vomiting was more in the $1^{\text {st }}$ semester whereas $3^{\text {rd }}$ semester students experienced more dizziness. Itching and rashes were seen in negligible number of students in each semester.
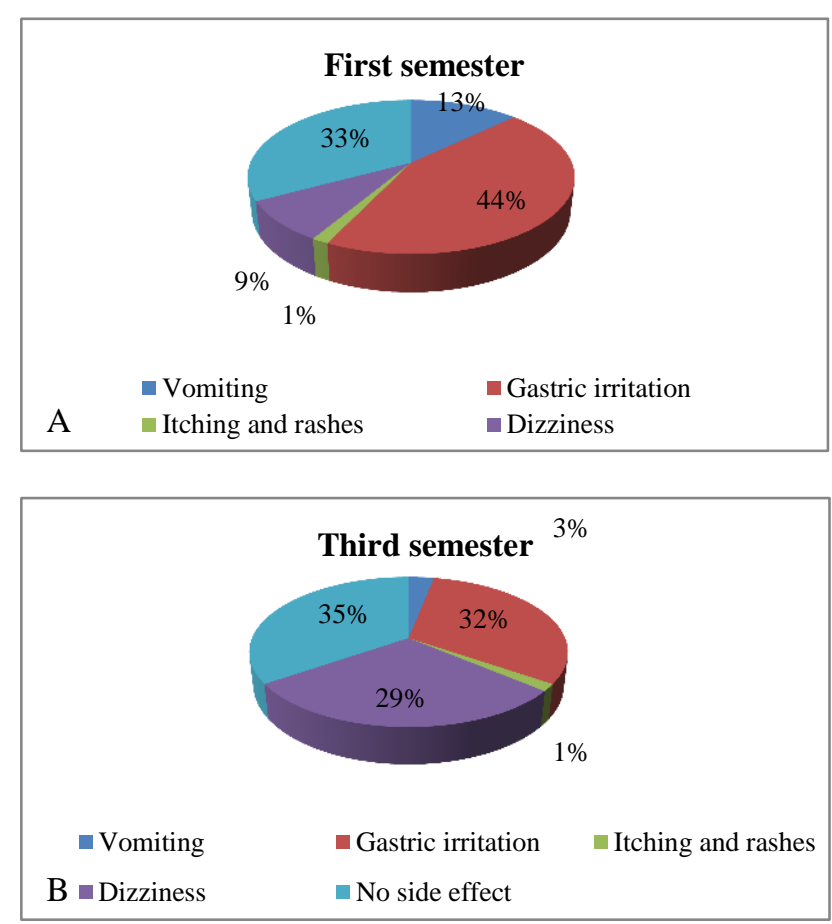

Figure 5 shows response against side effects.77\% and $60 \%$ of the students in both the students continued the drug. $7 \%$ and $16 \%$ of the students discontinued the drugs. $11 \%$ and $15 \%$ of the students reported the side effect to the physician. Very few students in both semesters either reduced the dose or changed to other drug.
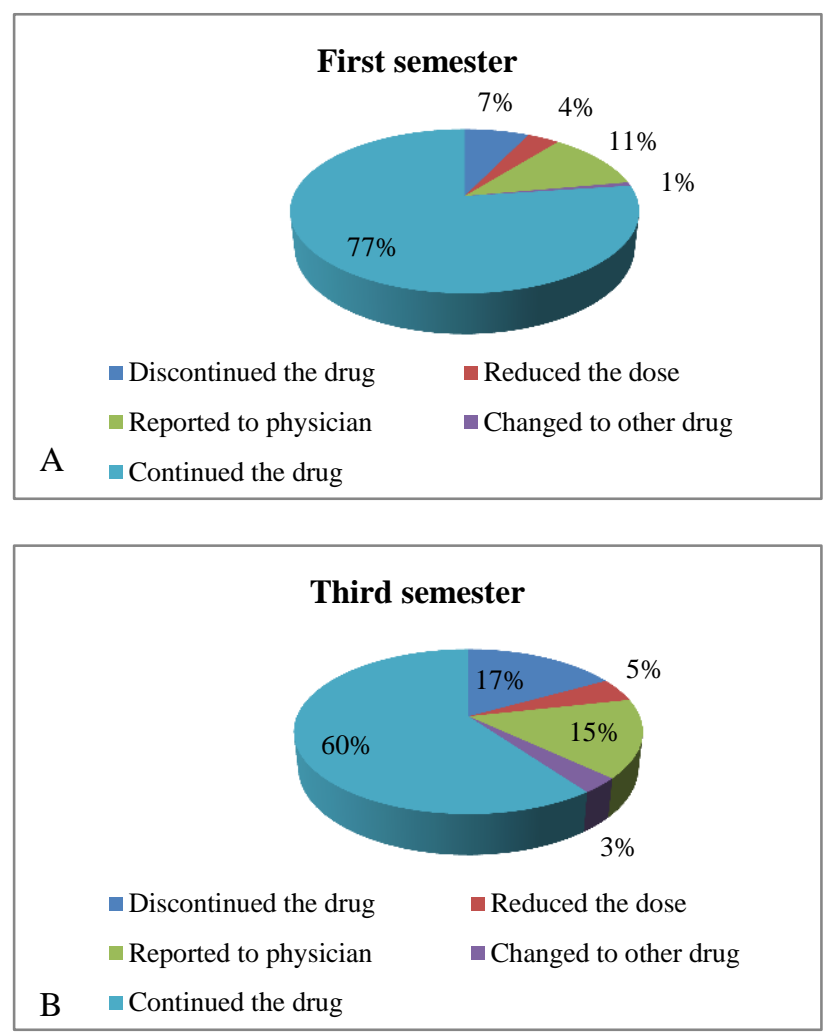

Figure 5 (A-B): Response against side effect.

$53 \%$ and $55 \%$ students of $1^{\text {st }}$ and $3^{\text {rd }}$ semester respectively are of the view that self-medication is not always acceptable. Avoidance of self-medication has been advocated by $33 \%$ and $29 \%$ of the students. Very few students in each semester believe that it is a good practice.

\section{DISCUSSION}

Self-medication is a prevalent practice all over India, more so among the medicos as they see themselves as future doctors. ${ }^{2}$

In both the semesters, there was no significant difference among the male and female students practicing self- medication $(p>0.05)$. This result matches with an earlier similar study done in Jharkhand. ${ }^{10}$ This result leads to the conclusion that there is no gender difference factor regarding knowledge of drugs and self-medication among the medicos.

Figure 4 (A-B): Side-effects. 
Most of the students in all the semesters indulge in selfmedication which is also evident from the result. A study in Jordan shows that $96 \%$ of the medicos used self- medication. ${ }^{11}$

Advice from seniors was the most important source of information for practicing self-medication $(\mathrm{p}<0.05)$. This is very high as compared to an earlier study from Jharkhand where it was $37 \%$ only. ${ }^{10}$ This is not a welcome trend as this may point to a decline in the reading habits of the students. Books and internet were the next most important source of information in the $1^{\text {st }}$ and $3^{\text {rd }}$ semester respectively.

The most commonly used analgesic by all students is paracetamol $(\mathrm{p}<0.05)$. A similar study in Jeddah, Saudi Arabia found that $47 \%$ of the students there used acetaminophen as a self-medicated analgesic whereas $50 \%$ of the students used non-steroidal antiinflammatory drugs (NSAIDs). ${ }^{12}$ This variation could be attributed to the differences in the study population due to difference in self-medication trends in different geographical regions. The reason behind this is that it is very safe and devoid of side effects like gastric irritation, nausea and vomiting. Use of aspirin is high in the $3^{\text {rd }}$ semester, which may be due to their knowledge as to how to avoid the side effects related to aspirin by taking it after meal and not taking it very frequently to avoid gastric bleeding.

Headache was the most common indication for using analgesics by both $1^{\text {st }}$ and $3^{\text {rd }}$ semester students in our study $(p<0.05)$. This is similar to the finding in an earlier study in RIMS which also found headache to be the most important indication for self-medication. ${ }^{10}$ Fever, menstrual pain and flu were other common indications for using self-medicated analgesics. Headache followed by common cold and dysmenorrhea was listed as the common causes of analgesic use in a study in Jeddah. ${ }^{12}$ Headache can be very discomforting at times and probably the urge to relieve the pain as soon as possible leads to self-medication of analgesics.

Quick relief followed by mild nature of the illness and time saving measures were important reasons for selfmedication of analgesics as seen in our study $(\mathrm{p}<0.0 .5)$. In contrast, in a Nigerian study in a private university, the main reason of self-medication were found to be the unfriendly attitude of the health care workers in the school clinic, busy schedule of the students was one of the common reasons seen among those students also. Distance of the hospital from the hostel and perceived inefficacy of the prescribed drugs were some of the other reasons noted. ${ }^{13}$

In our study, most of the students used a single tablet per day. Few students used more than one tablet and none of the student used more than three tablets per day. This is similar to an earlier study done in Jharkhand. ${ }^{10}$ In a study done in Saudi, most of the students used one tablets per day. ${ }^{14}$ Estimation of adequate dose of the medicine is very important as under dosing may not only be unable to cure the illness, but also create a chronic disease state. Overdosing on the other hand may lead to toxicity.

Self-medicated analgesics were taken by most of the students as and when requirement occurred. Most of them took it for a day and very few used self-medication for more than one week. A study in Saudi Arabia showed that most of the students used it monthly whereas very few of them used self-medication daily. ${ }^{15}$ This shows that students in this part of India are more aware of the side effects of long time use of analgesics. Misuse is more in the Saudi population indicating lack of knowledge of the effects of long term analgesic use.

A large number of students took analgesics after meal in an attempt to mitigate side effects like gastritis. Very few students used it before meal showing their lack of knowledge about the potential side effects and time of taking the analgesics. Some used it at non-specific time of the day. Quite a number of students used it during episodes of pain reflecting the severity of the condition.

Gastric irritation was the most important side effect encountered on analgesic use followed by dizziness and vomiting. These are the documented common side effects of analgesics, more due to NSAIDs. ${ }^{16}$

In our study, many of the students discontinued the drug in response to side effects. Some of them reported about these adverse drug reactions to the physicians.

In Nepal, $47 \%$ said that it was an acceptable practice whereas $36 \%$ said that practice of self-medication is not acceptable. This finding is different from our study which concludes that it is unacceptable by almost $50 \%$ of the students in both the semesters $(p<0.05) .{ }^{17}$ The unacceptability of self-medication is due to the fact that it may have grave consequences and may also influence their professional decision. Considering self-medication safe may be only possible when the person taking the drug has sufficient knowledge regarding the advantages, side effects and proper dose of the drugs. ${ }^{18}$

\section{CONCLUSION}

Self-medication practices are very prevalent in all geographical regions of the world. The same holds true for our part of the country, i.e., Jharkhand. More so, it is very popular among the medical students as it is pocket friendly and time saving also. But, sometimes improper diagnosis or treatment may lead to grave consequences. Hence, the value of expert opinion cannot be underestimated. In the present scenario, both the pros and the cons of self- medication should be taken into consideration and likewise decision should be taken regarding self-medication for the treatment of any 
medical condition. Proper knowledge and practical wisdom can be a major factor affecting this decision.

Funding: No funding sources

Conflict of interest: None declared

Ethical approval: The study was approved by the Institutional Ethics Committee

\section{REFERENCES}

1. Ezz NF, Ez-Elarab HS. Knowledge, attitude and practice of medical students towards self-medication at Ain Shams University, Egypt. J Prev Med Hyg. 2011;52(4):196-200.

2. Banerjee I, Bhaduri T. Self-medication practice among undergraduate medical students in a tertiary care medical college, West Bengal. J Postgrad Med. 2012;58(2):127-31

3. Kasulkar AA, Gupta M. Self-medication practices among medical students of a private institute. Indian J Pharm Sci. 2015;77(2):178-82.

4. Soroush A, Abdi A, Andayeshgar B, Vahdat A, Khatony A. Exploring the perceived factors that affect self-medication among nursing students: a qualitative study. BMC Nurs. 2018;17:35.

5. Mortazavi SS, Shati M, Khankeh HR, Ahmadi F, Mehravaran S, Malakouti SK. Self-medication among the elderly in Iran: a content analysis study. BMC Geriatr. 2017;17:198.

6. Yousef AMM, Al-Bakri AG, Bustanji Y, Wazaify M. Self-medication patterns in Amman, Jordan. Pharm World Sci. 2008;30:24.

7. Jagadeesh K, Chidananda KN, Revankar SP, Prasad NS. Study on self-medication among 2nd year medical students. 2015;4(1):164-7.

8. Alam N, Saffoon N, Uddin R. Self-medication among medical and pharmacy students in Bangladesh. BMC Res Notes. 2015;8:763.

9. Shah H, Patel R, Nayak S, Patel HR, Sharma D. A questionnaire-based cross-sectional study on selfmedication practices among undergraduate medical students of GMERS Medical College, Valsad, Gujarat. Int J Med Sci Public Health. 2018;7(4):249-54.

10. Kumari K, Toppo MS, Priyanki. Self-medication practices of over the counter analgesic drugs among medical students in a tertiary care hospital in Jharkhand, India. Int $\mathrm{J}$ Basic Clin Pharmacol. 2019;8:903-9.

11. Alzoubi KH, Khabour OF, Farah S. Patterns of selfmedication among medical and nonmedical University students in Jordan. Risk Manag Healthc Policy. 2018;11:169-76.

12. Ibrahim NK, Alamoudi BA, Baamer WO, AlRaddadi RM. Self-medication with analgesics among medical students and interns in King Abdulaziz University, Jeddah, Saudi Arabia. Pak J Med Sci. 2015;31(1):14-8.

13. Esan DT, Fasoro AA, Odesanya OE, Esan TO, Ojo $\mathrm{EF}$, Faeji CO. Assessment of self-medication practices and its associated factors among undergraduates of a private university in Nigeria. $\mathbf{J}$ Environ Public Health. 2018:5439079.

14. Karami NA, Altebainawi AF, Alfarki SA, Aldossari NB, Asiri AN, Aldahan MS, et al. Knowledge and attitude of analgesics use among Saudi population: A cross-sectional study. Int J Med Sci Public Health. 2018;7(2):137-43.

15. Al Saleh FM, Al Dawood KM, Omer AH. Analgesics misuse: a problem among Saudi female students. Int J Med Health Sci. 2018;7(4):151-6.

16. Borazan HN, Furst ED. Nonsteroidal antiinflammatory drugs. Disease- modifying antirheumatic drugs, non-opioid analgesics, and drugs used in gout. Basic Clin Pharmacol. 13th ed. New Delhi, India: McGraw Hill Education Private Limited; 620 .

17. Helal RM, Elwafa HAS. Self-medication in university students from the city of Mansoura, Egypt. J Environ Public Health. 2017:9145193.

18. Kumari K, Toppo MS, Kumar M. The practice of self-medication in diarrhoea among second year medical students in a tertiary care hospital in Jharkhand. IJPSR. 2018;9(11):1000-5.

Cite this article as: Kumari K, Gari M, Toppo MS, Soreng IA, Priyanki. Self-medication practices of over the counter analgesics among first and third semester undergraduate medical students in a tertiary care medical college, Jharkhand. Int J Basic Clin Pharmacol 2019;8:2614-9. 